\title{
Yes, The FDA Can MaKe You Say That: Why The FDA's PROPOSED NUTRITION FACTS LABEL CHANGES WiLl WithsTAND FiRST AMENDMENT CHALLENGES FROM FOOD INDUSTRY MEMBERS
}

\author{
Maggie C. Little*
}

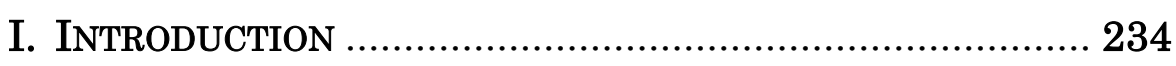

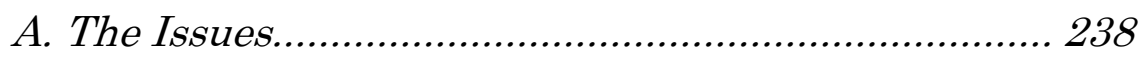

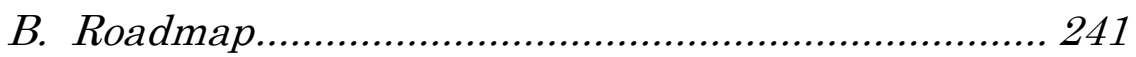

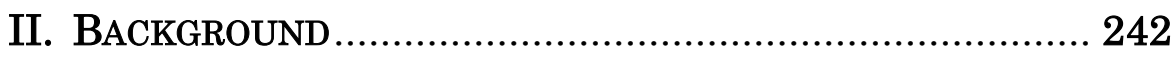

A. The FDA's Proposed Changes to the Nutrition ...... 242

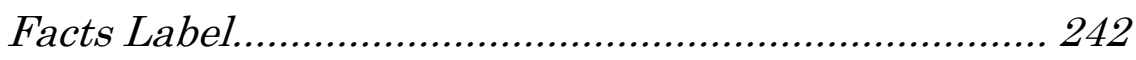

B. Added Sugar Disclosure....................................... 244

C. First Amendment Protected Speech ..................... 245

D. Central Hudson Standard Introduction ................. 247

E. R.J. Reynolds Tobacco Co. Under Central Hudson . 247

F. Trans Fatty Acids Under Central Hudson.............. 249

G. Zauderer Standard Introduction........................... 250

H. International Dairy Foods Association Under

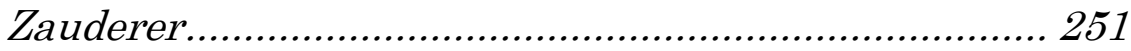

I. American Meat Institute Under Zauderer............... 252

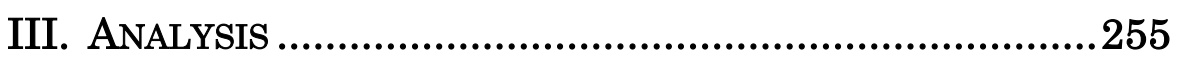

A. Commercial Speech Analysis ............................... 255

B. Zauderer or Central Hudson ................................. 255

1. Central Hudson Standard Analysis.......................... 256

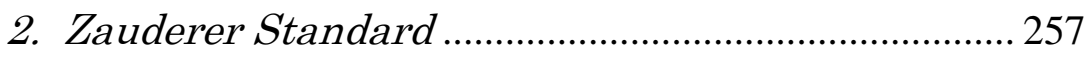

* J.D. Candidate, 2016, Indiana University Robert H. McKinney School of Law; M.H.S.A., 2013, University of Evansville; B.S., 2013, University of Evansville. 
C. Zauderer First Amendment Analysis ................... 258

1. Purely Factual ............................................................. 259

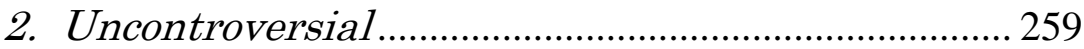

3. Legitimate Government Interest................................. 261

4. Disclosure Must Be Reasonably Related .................. 264

5. Disclosure Is Not Unjustified or Unduly

Burdensome 267

D. Final Policy Reasons for Implementing the

Proposed Rule ......................................................... 269

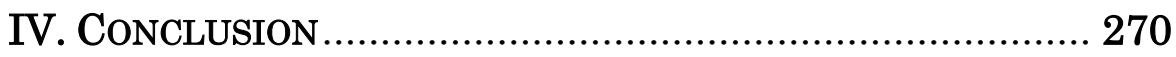

\section{INTRODUCTION}

In recent years, consumers have become increasingly concerned about the ingredients and overall nutritional content of foods they are eating. Such concerns often stem from weight-loss programs, food allergies, and environmental concerns. The nation has seen a number of movements in this direction ranging from calorie counting via mobile apps, ${ }^{1}$ and "gluten free" 2 diets to the overall "clean eating" ${ }^{3}$ concept.

1 Kathy Niedler, Self Tracking Fitness, Review of Popular MyFitnessPal App, iMedical Apps: MedPage Today, (Nov. 12, 2012) http://www.imedicalapps.com/2012/11/review-popular-myfitnesspal-appfitness/ [http://perma.cc/WFP7-T4TZ] MyFitnessPal is a mobile app that allows users to track daily intake of calories and nutrients by selecting foods from a database or by manually entering the information from the Nutrition Facts label.

2 Mayo Clinic Staff, Gluten-Free Diet, The Mayo Clinic http://www.mayoclinic.org/healthy-living/nutrition-and-healthy-eating/ in-depth/gluten-free-diet/art-20048530 [http://perma.cc/B7C9-QWDR] (last updated Nov. 25, 2014). A gluten free diet is a diet that excludes the protein gluten and is typically followed by those with Celiac disease, although the diet has more recently become popular among non-Celiac disease sufferers. Id.

3 Lauren Torrisi, What the Heck is Clean Eating? ABC News (Apr. 5, 2013), http://abcnews.go.com/blogs/lifestyle/2013/04/what-the-heck-isclean-eating [http://perma.cc/N4EL-JWY9]. (stating that "clean eating" is the concept that the shorter the ingredient list of a food, the better. The 
The FDA has stepped in with an attempt to assist consumers with understanding the nutritional content of foods in response to consumer interest to learn more about the nutrients in common foods. The FDA made such an attempt by a proposal to add more detailed nutrition information to Nutrition Facts labels, as well as a proposal for a restructured label to make the label easier for consumers to read and understand. ${ }^{4}$

In addition to assisting the individuals who are following strict diets, the FDA recognized the need to improve the accessibility of nutrition information for all consumers due to the current obesity epidemic throughout the United States. ${ }^{5}$ To address various health concerns, such as obesity and the chronic conditions associated with obesity, the FDA proposed updates to the Nutrition Facts labels of packaged food products to provide consumers with the necessary and important information to make healthy food choices. ${ }^{6}$

Among the updated information, the FDA hopes to implement a requirement of the disclosure of the amount of added sugar on the Nutrition Facts label as part of a major overhaul to the Nutrition Facts label. ${ }^{7}$ As support for the added sugar disclosure, the FDA asserted all the proposed changes to the Nutrition Facts label are necessary and impactful because recent studies have shown that the number of consumers that use the information on the Nutrition Facts label has grown since 2002,8 which is not surprising due to calorie counting, clean eating and gluten free trends. ${ }^{9}$ Further, the FDA concluded the new added

idea focuses on eating whole foods that lack artificial preservatives, sugars, and other additives.).

4 Proposed Changes to the Nutrition Facts Label, FDA, http://www.fda.gov/Food/GuidanceRegulation/GuidanceDocumentsRegul atoryInformation/LabelingNutrition/ucm385663.htm [http://perma.cc/ 9VPE-3AEP] (last updated July 27, 2015) [hereinafter "Proposed Changes"].

$5 \mathrm{Id}$.

$6 \mathrm{Id}$.

$7 \mathrm{Id}$.

$8 I d$.

9 Gluten-Free Diet Appeals to 30Percent of Adults, Survey Says, HUFFINGTON POST (Mar. 6, 2013), http://www.huffingtonpost.com/2013/ 03/06/gluten-free-diet_n_2818954.html [http://perma.cc/7V4P-GCTR] 
sugar disclosure requirement will encourage food manufacturers to reformulate products to include less overall added sugar. ${ }^{10}$

The necessity of such updates to the Nutrition Facts label was identified before the FDA stepped in with the proposed rule in 2014. In 2010, the Center for Science in the Public Interest ("CSPI") released a report that called for the reform of food labeling legislation. ${ }^{11}$ CSPI called for eight specific updates to the Nutrition Facts label in its report, largely because the label has not been updated since the passage of the Nutrition Labeling and Education Act of 1990 ("NLEA"). ${ }^{12}$ Further, CSPI asserted the updates to the label are essential because the current label from NLEA was not designed to prevent or reduce obesity. ${ }^{13}$

The FDA included some form of most of the changes recommended by CPSI in the proposed rule. ${ }^{14}$ CSPI recommended an update to the design of the Nutrition Facts label by increasing the font size of the word "calories," as well as changing the "amount per serving" statement. ${ }^{15}$ The organization also recommended a modification to the serving size for foods that are reasonably likely to be consumed by one person in a single sitting. ${ }^{16}$ Additionally, CSPI recommended an update to the serving size of foods to more closely reflect the larger portion sizes consumed today. ${ }^{17}$

(reporting that "[t]hirty percent of adults are interested in avoiding or cutting down in gluten in their diets."); Announcing 75 Million MyFitnessPal Users, Hello Healthy, MyFitnessPal Updates (Dec. 9, 2014), http://blog.myfitnesspal.com/announcing-75-million-myfitnesspalusers/ [http://perma.cc/EPQ6-8FR9]. MyFitnessPal claims to have 75 million registered users of the app worldwide as of 2014.

10 Proposed Changes, supra note 4.

11 Bruce Silverglade \& Ilene Ringel Heller, Food Labeling Chaos: The Case for Reform, THE CTR. FOR SCIENCE IN THE PUB. INTEREST 1 (Mar. 2010), http://www.cspinet.org/new/pdf/food_labeling_chaos_report.pdf. [http://perma.cc/L7N6-NB3X].

12 Id. at I-1.

$13 \mathrm{Id}$.

14 See generally, Food Labeling: Revision of the Nutrition and Supplement Facts Label, 79 Fed. Reg. 11880 (Mar. 3, 2014) (to be codified at 21 C.F.R. 101) [hereinafter "Food Labeling"]

15 Id. at I-2.

16 Id.

17 Silverglade \& Ringel Heller, supra note 11, at II-3. 
CSPI also proposed including the amount of added sugar to the label, as well as the creation of a recommended daily value for added sugar. ${ }^{18}$

Nearly four years after CSPI published the report highlighting the recommended updates to the Nutrition Facts label, the FDA published the proposed rule, "Food Labeling: Revision of the Nutrition and Supplement Facts Label" in the Federal Register on March 3, 2014.19 Additionally, the FDA published revisions to the 2014 Proposed Rule on July 17, 2015.20

First Lady Michelle Obama also expressed her support for an updated Nutrition Facts label with an endorsement of the FDA's proposed rule during an event for her "Let's Move!" campaign. ${ }^{21}$ During the event she emphasized the importance of labels that are easier for consumers, who have little or no nutrition knowledge to understand. ${ }^{22}$ She noted that consumer-friendly labels would help consumers make informed and healthy decisions based on the information provided in the new label. ${ }^{23}$ The First Lady also specifically applauded the added sugar disclosure by stating "[y]ou'll also learn where sugar in food comes from-if sugar in yogurt is added during processing or comes from fruits. This is a huge deal." 24

The campaign for the updated Nutrition Facts label also follows the passage of the front of package label requirements. ${ }^{25}$ Once food manufacturers started using front

18 Id. at II-1.

19. Food Labeling, supra note 14.

20 Food Labeling: Revision of the Nutrition and Supplement Facts Label: Supplemental Proposed Rule to Solicit Comment on Limited Additional Provisions, 80 Fed. Reg. 44303 (July 17, 2015) (to be codified at 21 C.F.R. 101) [hereinafter "Supplemental Proposed Rule"].

21 Sabrina Tavernise, New FDA Nutrition Labels Would Make Serving Sizes Reflect Actual Servings, N.Y. Times (Feb. 27, 2014), http://www.nytimes.com/2014/02/27/health/new-fda-nutrition-labels would-make-serving-sizes-reflect-actual-servings.html?_r=1., [http:// perma.cc/7ZNW-EBBT].

$22 I d$.

$23 I d$.

24 Id.

${ }^{25}$ Kathryn E. Hayes, Front of Package Nutrition Claims: Trustworthy Facts or Deceptive Marketing? Closing the Loopholes in Labeling, 19 CARDOZO J.L. \& GENDER 545, 550 (2013); See also Background 
of package labels, the government recognized a need for easier to understand Nutrition Facts labels because many consumers could not properly understand the Nutrition Facts labels and therefore relied on sometimes misleading front of package labels. ${ }^{26}$ Fruit snacks often appear to be a healthy snack choice for children based on the front of package label that boasts, "made with real fruit." 27 However, after a proper examination of the ingredients label, these seemingly healthy fruit snacks are filled with corn syrup-a form of added sugar that increases the calories in the snack. ${ }^{28}$ If the consumer had been able to find the high amount of added sugar conveniently located on the Nutrition Facts label, the mistake of consuming a snack high in added sugar that claims to be "made with real fruit" could have been avoided. ${ }^{29}$

\section{A. The Issues}

Despite the urgent need for updated Nutrition Facts labels with an added sugar disclosure, the FDA faces pushback from food manufacturers. The FDA was required by law to allow time for comments from the public after the 2014 proposed rule was published, and must consider and evaluate all comments before promulgating a final rule. ${ }^{30}$

Information on Point of Purchase Labeling, FDA (Oct. 2009) http://www.fda.gov/Food/IngredientsPackagingLabeling/LabelingNutriti on/ucm187320.htm [http://perma.cc/S9UJ-4ECQ] [hereinafter Point of Purchase Labeling]. (Front of package ("FOP") labels often include nutritional information in addition to health or nutrient content claims and the FOP labels may also be in the form of graphics that indicate the food is a "healthy choice," although evidence suggests that the graphics can give the products an "overrated" view of healthiness).

${ }^{26}$ Hayes, supra note 25 , at 550.

27 Id. at 564.

28 Id. at 565.

29 Id.

30 Administrative Procedures Act, 5 U.S.C $§ 553$ (2015) (“...the agency shall give interested persons an opportunity to participate in the rule making through submission of written data, views, or arguments"). Food Labeling, supra note 14 at 11880 (Initially, the comment period was open for 90 days after the proposed rule was published on March 3, 2014). Food Labeling: Revision of the Nutrition and Supplement Facts Labels; Extension of Comment Period, 79 Fed. Reg. 30055 (May 27, 2014). (The FDA extended the comment period to August 1, 2014 in response to many 
Further, the 2015 supplemental proposed rule reopened the comment period in order to solicit additional comments for a limited number of provisions that were revised based on new evidence and some of the public comments. ${ }^{31}$

In many of the public comments that opposed the 2014 proposed rule, there was an assertion that the mandatory disclosure of added sugar infringes on First Amendment rights to free speech, specifically the right to "refrain from speaking." 32 Ocean Spray Cranberries, Inc. asserted in their comment that the added sugar disclosure will fail First Amendment scrutiny. ${ }^{33}$ In addition to alleging First Amendment violations, food industry members also claimed the disclosure is unwarranted and misleading. ${ }^{34}$ Based on such comments, it seems fair to assume challenges may be brought against the disclosure because some food industry members consider it controversial. ${ }^{35}$ The food industry had similar comments and concerns when the mandatory disclosure of trans fats was introduced in 2003.36 The

requests for the extension because the 90-day period was not sufficient time to develop thoughtful comments and suggestions).

31 Supplemental Proposed Rule supra note 20, at 44311.

32 Glenn G. Lammi, FDA's "Added Sugar" Labeling Proposal: More Information Isn't Always Better (Or Legal), ForBES (Sept. 8, 2014), http://www.forbes.com/sites/wlf/2014/09/08/fdas-added-sugar-labelingproposal-more-information-isnt-always-better-or-legal/ [http://perma.cc/ U3KT-ZAUJ].

33 Public Comment from Ocean Spray Cranberries, Inc. on Proposed Rule: Food Labeling: Revision of the Nutrition and Supplement Facts Labels (Aug. 1, 2014), available at http://www.regulations.gov/ \#!documentDetail;D=FDA-2012-N-1210-0388 [http://perma.cc/7S772YK7].

${ }^{34}$ Public Comment from Decas Cranberry Products on Proposed Rule: Food Labeling: Revision of the Nutrition and Supplement Facts Labels (Aug. 1, 2014), available at http://www.regulations.gov/ \#!documentDetail;D=FDA-2012-N-1210-0085 [http://perma.cc/7ZPA36MP] ("...the inclusion of 'added sugar' as a separate item within the nutrition facts panel, is scientifically unwarranted, and will create confusion with consumers as to the healthful properties of cranberry products.").

35 Tavernise, supra note 21.

36 Food Labeling: Trans Fatty Acids in Nutrition Labeling, Nutrient Content Claims, and Health Claims, 68 Fed. Reg. 41434, 41439 (July 11, 2003) [hereinafter "Trans Fatty Acids"]. ("Several general comments 
previous comments on the trans fat disclosure support the likelihood of formal First Amendment challenges to the added sugar disclosure.

The first issue with respect to the added sugar disclosure that must be resolved is whether it would survive such First Amendment challenges. The resolution of such a challenge requires that a court first determine whether the labeling disclosure is commercial speech ${ }^{37}$. Once the disclosure is regarded as commercial speech, the court must determine the appropriate standard to apply in analyzing the disclosure. ${ }^{38}$ Similar commercial speech challenges, such as warning labels on tobacco products, were held under the standard created in Central Hudson Gas \& Electric Corp. v. Public Service Commissioner.

However, recent litigation regarding meat product labeling was held to the more lenient standard created in Zauderer v. Office of Disciplinary Counsel of Supreme Court. In the 2014 D.C. Circuit case, American Meat Institute v. USDA, the challenged country-of-origin disclosure on meat products was held to the reasonable relationship Zauderer standard, discussed in further detail later in this Note. ${ }^{39}$ The decision was declared to be a "win for public health" because it opened the possibility of holding future food labeling challenges to the same standard. ${ }^{40}$

were received asserting that the agency's action to mandate labeling is subject to review under the First Amendment").

37 See Lucien J. Dhooge, The First Amendment and Disclosure Regulations: Compelled Speech or Corporate Opportunism?, 51 AM. Bus. L.J. 599 (2014).

38 Courts have historically analyzed commercial speech First Amendment challenges under the standard created in Central Hudson or Zauderer, discussed in further detail later in this Note.

39 Jonathan H. Adler, En banc D.C. Circuit Upholds USDA Countryof-Origin Labeling Rule, VOLOKH CONSPIRACY (July 30, 2014), http://www.washingtonpost.com/news/volokh-conspiracy/wp/2014/07/30/ en-banc-d-c-circuit-upholds-usda-country-of-origin-labeling-rule/ [http:// perma.cc/8MAN-MMVD].

40 Kerry Cork, Court Decision on "Mandatory Disclosure" Could be a Big Win for Public Health, Network For Public Health LaW BloG (Aug. 6, 2014, 11:40 AM), https://www.networkforphl.org/ the_network_blog/2014/08/06/480/court_decision_on_mandatory_disclos ure_could_be_a_big_win_for_public_health, [http://perma.cc/W2UV7H5G]. 
Even though some food industry members asserted the added sugar disclosure should be held to the Central Hudson standard, ${ }^{41}$ a court would likely hold the FDA's proposed added sugar disclosure to the Zauderer standard because of the American Meat Institute analysis. Through the application of the reasonable relationship test from Zauderer, a court would likely find the added sugar disclosure to survive First Amendment challenges due to the many legitimate government interests for providing information about the amount of added sugar in a product for consumers.

\section{B. Roadmap}

This Note will begin by exploring the FDA's proposed rule, "Food Labeling: Revision of the Nutrition and Supplement Facts Labels," 42 with an emphasis on the added sugar disclosure. Next, the Note will transition into an examination of First Amendment standards in the context of commercial speech and an evaluation of the standards that courts have used when examining such disclosures.

As a continuation of the First Amendment evaluation, the Note will also discuss some of the most recent food labeling litigation and provide an analysis of the court's review under the respective standard applied by the court. After evaluating recent case law regarding food labeling, a determination of whether the Central Hudson or Zauderer standard should apply to the disclosure will be made.

Finally, the Note will analyze the added sugar disclosure requirement under the five-prong reasonable relationship test from Zauderer and explain the reasons why the disclosure will withstand First Amendment challenges under this standard. The final section will also provide a few supporting policy reasons for the proposed rule and explain

41 Public Comment from The Corn Refiner's Association on Proposed Rule: Food Labeling: Revision of the Nutrition and Supplement Facts Labels (Aug. 1, 2014), available at http://www.regulations.gov/ \#!documentDetail;D=FDA-2012-N-1210-0455 [http://perma.cc/RZ4GRBYB] (asserting the added sugar disclosure would fail First Amendment scrutiny under the four prong test from Central Hudson).

42 Food Labeling, supra note 14, at 11880. 
why the FDA should move forward with a final rule, regardless of potential First Amendment challenges.

\section{BACKGROUND}

The FDA published an initial proposed rule, "Food Labeling: Revision of the Nutrition and Supplement Facts Label" in the Federal Register on March 3, 2014 and published revisions to the initial proposed rule on July 17, 2015.43 The FDA's main goal of the proposed rule was to update the regulations to better assist consumers in maintaining healthy eating practices by improving "how the information is presented to consumers." 44 The FDA aimed to achieve such a goal with three major categories of proposed changes to the Nutrition Facts label.

\section{A. The FDA's Proposed Changes to the Nutrition Facts Label}

The first major category of changes is designed to create a "greater understanding of nutrition science ${ }^{45}$ by adding the amount of added sugar to the label, an update to the "percentage of daily value" for some nutrients, and removal of the line "calories from fat." 46 By modifying the label, the FDA hopes to provide consumers with the necessary information to understand the link between the nutrients and calories consumed and obesity. ${ }^{47}$ In addition, the update to the percentage of daily values for some nutrients, such as sodium, dietary fiber, and vitamin $\mathrm{D}$, will help consumers understand the role the nutrients play in their overall daily diet. 48

43 Id.; Supplemental Proposed Rule, supra note 20, at 44303.

44 Food Labeling, supra note 14, at 11880.

45 Proposed Changes, supra note 4.

46 See id.; Nutrition Facts Label: Proposed Changes Aim to Better Inform Food Choices FDA (Feb. 2014), http://www.fda.gov/downloads/ ForConsumers/ConsumerUpdates/UCM395422.pdf [http://perma.cc/ TK6P-ELRN].2X3X-PAK5]. (The FDA has proposed the removal of "calories from fat" because evidence shows the type of fat is more important than the total amount of fat).

47 Proposed Changes, supra note 4.

48 Id. 
The second major category of changes to the Nutrition Facts label is intended to update the "serving size requirements." requirements for certain package sizes, '50 including modifying serving sizes for food and drinks typically consumed in one sitting. ${ }^{51}$ Currently, a twenty-ounce bottle of soda is labeled as more than one serving. ${ }^{52}$ With the proposed changes to the Nutrition Facts label, the soda would be labeled as one single serving because it is most often consumed in one sitting, by one consumer. ${ }^{53}$

Additionally, the serving sizes of certain foods and drinks will be updated to reflect the larger portions Americans consume today. ${ }^{54}$ For example, a pint of ice cream is currently labeled as four servings-about half a cup per serving. 55 The FDA proposed a change to the number of servings in a pint of ice cream to two servings in order to more accurately represent the larger portions consumed by Americans. ${ }^{56}$

Finally, the last category of proposed changes to the Nutrition Facts label is intended to create a "refreshed design ' 57 with more emphasis on the serving size and calorie content of the label. ${ }^{58}$ Serving size and calorie content are essential pieces of information for consumers to understand in order to make healthy choices to prevent obesity and other chronic conditions. ${ }^{59}$ The new label would also relocate the percentage of daily value, another important piece of information used to make healthy choices, to the left of the nutrients so that it will also quickly attract consumer attention. ${ }^{60}$
49 Id.
$50 \mathrm{Id}$.
51 Id.
$52 I d$.
$53 \mathrm{Id}$.
54 Id.
$55 \mathrm{Id}$.
56 Id.
57 Id. at 4.
$58 \mathrm{Id}$.
59 Id.
$60 I d$. 


\section{B. Added Sugar Disclosure}

Based on a review of the public comments to the 2014 proposed rule, it appears the added sugar disclosure sparked the most conversation and will therefore be reviewed with the most detail in this Note. The FDA proposed the amount of added sugar in a food should be included in the Nutrition Facts label, indented under the line where "sugar" is currently listed. ${ }^{61}$ The FDA proposed the disclosure based on the updated recommendation to reduce the number of calories consumed from excess solid fat and added sugars, ${ }^{62}$ as well as a recommendation of the amount of energy intake that should come from added sugars. ${ }^{63}$ Currently, the Institute of Medicine ("IOM") Dietary Reference Intake Report recommends a maximum of twenty-five percent of energy intake from added sugars, ${ }^{64}$ based on evidence that a high intake of added sugars decreases the intake of other more important nutrient dense foods. ${ }^{65}$

Along with the updated dietary recommendations, the FDA also cited consumer awareness as a major support for the added sugar disclosure. ${ }^{66}$ The FDA asserted that without the declaration of added sugars, consumers are unable to compare the amount of non-naturally occurring sugar in foods, such as fruit juices and yogurt. ${ }^{67}$ Forms of added sugar are often listed in the ingredients section of food labels under complex chemical names that many consumers do not understand or recognize as a form of sugar. 68

Finally, the FDA provided four additional reasons to include the disclosure of added sugars on the Nutrition Facts label to improve consumer awareness, including:

61 Id.

62 Food Labeling, supra note 14, at 11903. (“...to meet nutrient needs within an individual's calorie limits, a key recommendation of the 2010 DGA is to reduce the intake of calories from solid fats and added sugars").

$63 \mathrm{Id}$. at 11902.

64 Id.

$65 I d$.

66 Id. at 11904.

67 Id.

$68 I d$ 
(1) The variability in ingredients used, (2) the need for consumers to have a consistent basis on which to compare products, (3) the need for consumers to identify the presence or absence of added sugars, and (4) when added sugars are present, the need for consumers to identify the amount of added sugars added to the food. 69

Additionally, one of the revisions contained in the 2015 Supplemental Rule would also require a daily recommended value ("DRV") for added sugars to be displayed on the Nutrition Facts label. 70 The FDA initially rejected this idea in the 2014 proposed rule based on a lack of evidence for the establishment of a DRV. ${ }^{71}$ However, the 2015 Dietary Guidelines Advisory Committee performed additional updated research and suggested the label should include a declaration of a percent of daily value for added sugars. ${ }^{72}$

\section{First Amendment Protected Speech}

After establishing a foundation for why the FDA believes the added sugar disclosure on the Nutrition Facts label is necessary, it is essential to establish the foundation of the challenges that may be brought against the disclosure. A discussion of the types of First Amendment protected speech and how they are distinguished is necessary to understand why the food industry opposes the disclosure.

A First Amendment challenge brought by the food industry to protect its right to not speak or right to not disclose information would fall under the context of commercial speech. The Supreme Court classifies commercial speech as "speech which does no more than propose a commercial transaction," 73 and later extended the definition to include speech "related solely to the economic

69 Id.

70 Supplemental Proposed Rule, supra note 20, at 44308.

71 Food Labeling, supra note 14, at 11902.

72 Supplemental Proposed Rule, supra note 20, at 44307.

73 Dhooge, supra note 37, at 606-07 (quoting Pittsburgh Press Co. v. Pittsburg Comm'n on Human Relations, 413 U.S. 376, 386 (1973)). 
interests of the speaker and its audience."74 The Court also included speech in which the transaction was "the core notion of commercial speech." 75

Commercial speech is afforded a different type of protection than individual speech and can be restricted in ways that individual speech cannot be restricted. ${ }^{76}$ Such restriction may be in the form of a disclosure of additional information, warnings and any disclaimers that would be helpful in preventing deception in consumers. ${ }^{77}$

The idea of different restrictions for commercial speech is based on the theory that the government has an interest in ensuring "the flow of truthful and legitimate commercial information is unimpaired."78 Commercial speech can also be considered compelled speech, subject to government restrictions and requirements. ${ }^{79}$ In a corporate or commercial context, compelled speech can be generally categorized as speech the government requires of the corporation. 80

Two standards developed by the Supreme Court are typically used for evaluating whether commercial speech is protected under the First Amendment. In recent years, courts appear to be split in deciding the standard to apply to the different types of commercial speech, which has led to controversy over the issue. Both standards, the stricter from the 1980 case, Central Hudson Gas \& Electric Corporation v. Public Service Commissioner, and the more lenient from the 1985 case, Zauderer v. Office of the Disciplinary Counsel of Supreme Court, may be applied to speech restrictions or compelled speech.

${ }^{74}$ Id. at 607 (quoting Cent. Hudson Gas \& Elec. Corp. v. Pub. Serv. Comm'n, 447 U.S. 557, 561 (1980)).

75 Id. (quoting Bolger v. Youngs Drug Prods. Corp., 463 U.S. 60, 66 (1983)).

76 Id. at 606.

77 Id.

78 Id. (quoting Va. State Bd. of Pharmacy v. Va. Citizens Consumer Council, Inc., 425 U.S. 748, 771 n.24 (1976)).

79 Id. at 611.

80 Id. at 609-611. 


\section{Central Hudson Standard Introduction}

The standard from Central Hudson has been used for commercial speech cases related to compelled speech in the form of labeling, however there is concern as to whether it is the appropriate standard to apply in such a situation. ${ }^{81}$ The standard was most recently and notably applied to the compelled speech of graphic warning labels on cigarette packaging in R.J. Reynolds Tobacco Company v. FDA, discussed further in this section. ${ }^{82}$ Additionally, the FDA also included a brief First Amendment analysis of the mandatory trans fat disclosure on the Nutrition Facts label under the Central Hudson standard when it published the final rule in $2003 .{ }^{83}$

In the Central Hudson decision, the Supreme Court developed a four-part intermediate scrutiny test used to analyze commercial speech. ${ }^{84}$ The four-part test begins with a determination of whether the speech concerns "lawful activity" that "must not be misleading." 85 Next, the government interest in restricting the speech must be substantial. ${ }^{86}$ Third, the means used to restrict or compel the speech must directly advance the substantial government interest, and finally, the means must not be "more extensive than necessary to serve that interest." 87

\section{E. R.J. Reynolds Tobacco Co. Under Central Hudson}

The proposed graphic warning labels for tobacco products in R.J. Reynolds Tobacco failed the First Amendment intermediate scrutiny test under the Central Hudson

81 Id. at $618-619$.

82 R.J. Reynolds Tobacco Co. v. FDA, 696 F.3d. 1205, 1209 (D.C. Cir. 2012) (the graphic warnings contained a graphic photo depicting the negative effects of tobacco use, as well as the phone number for the "National Cancer Institute's Network of Tobacco Cessation Quitlines").

83 Trans Fatty Acids, supra note 36, at 41439.

84 Dhooge, supra note 37, at 616.

85 Cent. Hudson Gas \& Elec. Corp. v. Pub. Serv. Comm'n, 447 U.S. 557,566 (1980).

86 Id.

87 Id. 
standard. ${ }^{88}$ In 2012, the Family Smoking and Tobacco Prevention Act directed new regulations to be issued by the FDA that required new textual, as well as graphic warnings on all tobacco product packaging. ${ }^{89}$ The graphic warning labels contained "color graphics depicting the negative health consequences of smoking." 90 The FDA's primary goal in implementing such graphic warnings was "to effectively convey the negative health consequences of smoking on cigarette packages and in advertisements." 91

Once the FDA implemented a final rule, "Big Tobacco" filed suit, alleging First Amendment violations. ${ }^{92}$ Before addressing the specific First Amendment challenges, the court determined that the Central Hudson standard was the appropriate level of scrutiny to apply to the graphic warnings. ${ }^{93}$ The court's determination rested on the finding that the warnings were not purely factual and uncontroversial, nor were the warnings intended to correct false or misleading claims made by the tobacco companies. ${ }^{94}$

The court evaluated the warnings under the Central Hudson standard and found the FDA was able to show the purported interest of the graphic labels in reducing smoking rates was substantial. 95 However, the analysis ended at the next prong because the FDA was unable to produce a "shred of evidence" that the graphic warnings would directly advance the substantial interest. 96 Upon failing to provide substantial evidence that the graphic warnings would directly advance the substantial interest as required by the Administrative Procedure Act, the FDA's graphic warnings failed intermediate scrutiny under Central Hudson. ${ }^{97}$

In the dissenting opinion of the decision, Circuit Judge Rodgers argued the warnings should have been held to the lesser standard from Zauderer because the court failed to

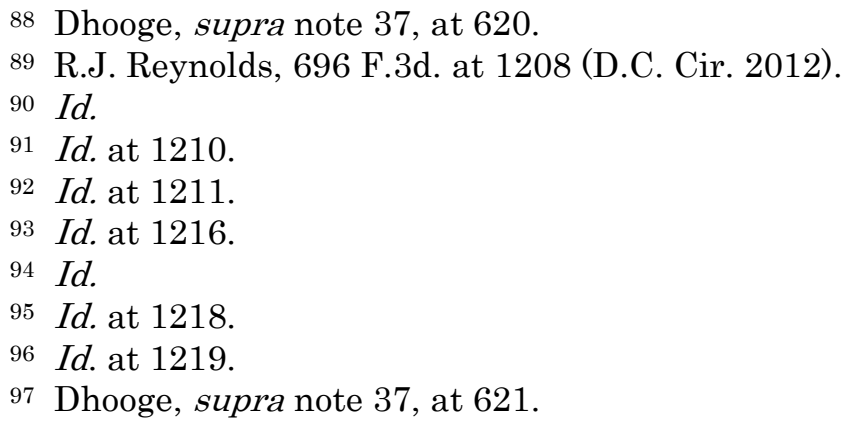


consider the tobacco companies' history of deceptive marketing. ${ }^{98}$ Judge Rodgers also asserted the warnings should have been held to the Zauderer standard because they contained "factually accurate information and addressed misleading speech." 99

\section{F. Trans Fatty Acids Under Central Hudson}

Although there was no litigation regarding the mandatory disclosure of trans fatty acids on the Nutrition Facts label, the FDA still engaged in a brief First Amendment analysis under the intermediate scrutiny standard from Central Hudson in the final rule, published on July 11, 2003.

The FDA issued a proposed rule on November 17, 1999 that called for the amount of trans fats to be disclosed on the Nutrition Facts label. ${ }^{100}$ The FDA based the proposal for the trans fats disclosure on the label on recent evidence that showed the "consumption of diets containing trans fatty acids...resulted in increased serum low-density lipoprotein cholesterol, [LDL-C] a major risk factor for [coronary heart disease]."101

In response to the many comments claiming the mandatory disclosure of trans fat on the Nutrition Facts label violated the First Amendment, the FDA included a brief analysis of how the disclosure would pass a First Amendment challenge under the Central Hudson standard in the final rule. The disclosure was related to lawful activity and not misleading and therefore passed the first prong of the standard. ${ }^{102}$ According to the FDA, the disclosure also satisfied the second prong because the FDA's interest in requiring the amount of trans fat on the label was clearly substantial. ${ }^{103}$

98 R.J. Reynolds Tobacco, 696 F.3d. at 1222 (Rodgers, J., dissenting).

99 Id.

100 Trans Fatty Acids, supra note 36, at 41435.

${ }_{101} I d$.

102 Id. at 41439.

103 Id. ("[The] FDA's interest is substantial for at least two reasons....substantial interest in protecting and promoting public health and in preventing consumer deception by ensuring accuracy and completeness of trans fat information in labeling."). 
The FDA asserted the mandatory disclosure would pass the third prong as well because it directly advanced the government interest when consumers relied on the information in the Nutrition Facts label in order to maintain healthy dietary practices. 104 Finally, the trans fat disclosure passed the fourth prong of Central Hudson because it was not more extensive than necessary to serve the FDA's interest. 105 The FDA asserted the disclosure was not extensive because it contained "truthful, factual, noncontroversial information about the presence or absence and amount of trans fat in food" that would assist consumers with choosing foods that will lower their risk of coronary heart disease. ${ }^{106}$

The FDA claimed that the trans fat disclosure would pass intermediate scrutiny under Central Hudson, but also stated that it was likely not even necessary for the disclosure to satisfy the test. 107 The FDA claimed the trans fat disclosure should not have to pass the Central Hudson standard because it is compelled commercial speech rather than a prohibition on speech in which Central Hudson typically applies. ${ }^{108}$ The FDA's assertion that the mandatory disclosure should not be held to the strict standard of Central Hudson may provide insight into which standard will apply to the FDA's proposed added sugar disclosure.

\section{G. Zauderer Standard Introduction}

In addition to the Central Hudson standard, courts have also used the more lenient standard from Zauderer to analyze commercial speech cases. Zauderer was decided after Central Hudson and provides an easier path for the government to pass when requiring a disclosure of additional information. 109 The Supreme Court developed a reasonable relationship test in Zauderer based on the theory that "rights are adequately protected as long as [the] disclosure requirements are reasonably related to the State's interest in

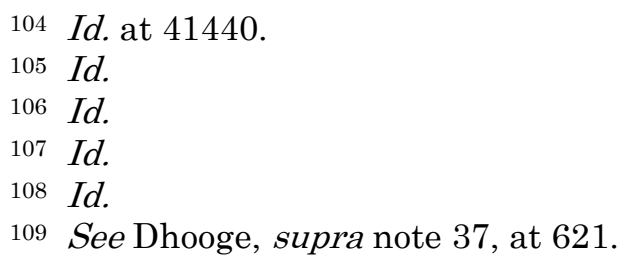


preventing deception of consumers." 110 The reasonable relationship test consists of five prongs used to determine whether government compelled speech violates First Amendment protection for commercial speech. 111

The first two prongs of the reasonable relationship test require the compelled speech to be "purely factual" and "uncontroversial."112 Speech that contains "accurate factual information" has been found to satisfy the first two prongs. ${ }^{113}$ The third prong mandates a "legitimate government interest" for requiring the speech or disclosure. ${ }^{114}$ The fourth prong requires the compelled speech or disclosure to also be "reasonably related" to the legitimate interests, and finally, the compelled speech or disclosure must not be "unjustified or unduly burdensome" in order to satisfy the fifth prong. ${ }^{115}$

\section{H. International Dairy Foods Association Under Zauderer}

International Dairy Foods v. Boggs is a 2010 Sixth Circuit case involving composition claims and label disclosures on dairy products. The Ohio Department of Agriculture developed regulations to address the claims of "rbST Free" used on dairy products that contained milk from cows not treated with rbST. 116 The Department required a disclosure that addressed the FDA's findings of no significant difference between milk from cows treated with rbST and milk from cows not treated with the hormone. ${ }^{117}$ While the court (1985).

110 Zauderer v. Office of Disciplinary Counsel, 471 U.S. 626, 651

111 Dhooge, supra note 37, at 624.

112 Id.

113 Id.

114 Id.

115 Id.

116 Int'l Dairy Foods Ass'n v. Boggs, 622 F.3d. 628, 640 (6 $6^{\text {th }}$ Cir. 2010) (rbST is a genetically engineered hormone sometimes given to cows to increase milk production. Dairy producers were using the phrase "rbST Free" on labels and the FDA required them to disclose that there has been no evidence that shows a compositional difference between milk from treated and untreated cows).

117 Id. at 632. (The department recommended a disclosure that stated, "the FDA has determined that no significant difference has been 
evaluated the compensation claim under the Central Hudson standard, it evaluated the disclosure claim under the Zauderer standard. ${ }^{118}$

The court determined the disclosure was reasonably related to the agency's interest in preventing consumer deception because some commentators pointed out that consumers were confused about what substances are or are not in the dairy products they purchased. ${ }^{119}$ Although the court concluded the actual disclosure was reasonably related to the interest, it found that the required placement and format of the disclosure lacked rational basis. ${ }^{120}$

The court also addressed whether the disclosure was unduly burdensome. In addressing the last prong of Zauderer, the court found the disclosure was not unduly burdensome because it would be identical to disclosures used by other states once the ban on the use of asterisks in the disclosure was lifted.121 Although the disclosure from International Dairy Foods does not explicitly pass the Zauderer standard, it serves as an excellent example of how courts apply this standard to government compelled speech.

\section{American Meat Institute Under Zauderer}

American Meat Institute v. USDA is the most recent food labeling case that could serve as a guide for any future litigation related to the FDA's required disclosure of added sugar on the Nutrition Facts label. American Meat Institute involved a First Amendment challenge by members of the American Meat Institute ("AMI") against the USDA for the implementation of a rule that required the country-of-origin

shown between milk derived from rbST-supplemented and non-rbSTsupplemented cows.").

118 Id. at 641. ("there are material differences between purely factual and uncontroversial disclosure requirements and outright prohibitions on speech").

119 Id. at 642.

$120 I d$. at 643. (The disclosure was required to be in the exact font, case, style, color and at least half the size as the production claim and not linked to an asterisk after the claim).

121 Id. 
of certain meat products to be disclosed on the label. ${ }^{122}$ The District Court applied the Zauderer reasonable relationship test to the country-of-origin disclosure and the D.C. Circuit affirmed the use of Zauderer for the disclosure. ${ }^{123}$

In an attempt to reject the standard applied by the District Court, plaintiffs asserted that Zauderer could not apply outside of government interests to prevent consumer deception. ${ }^{124}$ The plaintiffs instead asserted the stricter standard of Central Hudson should have applied to the mandatory disclosure. ${ }^{125}$ The D.C. Circuit rejected the plaintiffs' contention and instead held "[t]o the extent that other cases in this circuit may be read as holding to the contrary and limiting Zauderer to cases in which the government points to an interest in correcting deception, we now overrule them." 126

When applying the reasonable relationship test from Zauderer, the court first evaluated whether the government had a substantial interest in requiring the country-of-origin disclosure. ${ }^{127}$ Throughout the evaluation, the court found several substantial government interests, even though Zauderer only requires legitimate interests based on consumer choice, consumer interest, and consumer health concerns; therefore, the disclosure was reasonably related to such legitimate interests. ${ }^{128}$

The court then added that the country-of-origin disclosure was purely factual and uncontroversial. ${ }^{129}$ Absent any allegations by AMI that the disclosure would be unduly burdensome, the court held the disclosure was not unduly

122 Am. Meat Inst. v. United States Dep't of Agric., 760 F.3d. 18, 20

(D.C. Cir. 2014).
123 Id.
124 Id.
125 Id.
126 Id.
127 Id. at 23.
128 Id.

129 Id. at 27. (AMI did not contest that the disclosure was not purely factual, but did assert it was controversial. The court rejected AMI's controversial assertion because it is not of the category of facts that are so one-sided or incomplete that they could not be uncontroversial). 
burdensome. ${ }^{130}$ The country of origin disclosure therefore survived First Amendment challenges under Zauderer.

To demonstrate how American Meat Institute would serve as a guide for any litigation involving the added sugar disclosure, it is important to note the government interests for requiring the country-of-origin disclosure are similar to the government interests for requiring the added sugar disclosure. The two interests will be compared later in the Note, but a brief introduction to the government interests of country of origin labeling appropriately follows.

As noted above, the government interests in requiring country of origin labeling were based on consumer choice, interest and health concerns. First, the more detailed label with the disclosure gives consumers the power to choose American made products. ${ }^{131}$ The government has an interest in providing consumers with the necessary information to be aware of where the food came from, especially when this expectation has been long required of other non-food products. ${ }^{132}$ Finally, the government has an interest in providing consumers with the information necessary to choose meat from countries of their choice, based on individual health concerns and concerns related to food-borne illness. ${ }^{133}$

The Central Hudson and Zauderer standards developed by the Supreme Court are still used by courts for compelled speech cases today as shown by R.J. Reynolds Tobacco, International Dairy and American Meat Institute. ${ }^{134}$ Although R.J. Reynolds used the Central Hudson standard, American Meat Institute is evidence that courts are moving toward applying the more lenient Zauderer standard to government compelled speech situations, possibly changing the outcome of commercial speech cases.

130 Id. at 23 .

131 Id. at 23.

132 Am. Meat Inst., 760 F.3d. at 23. (“...country-of-origin label mandates indeed have a long history. Congress has been imposing similar mandates since 1890, giving such rules a run just short of 125 years.").

133 Id.

134 Dhooge, supra note 37, at 620. 


\section{ANALYSIS}

In order to determine whether the FDA's proposed added sugar disclosure would survive a First Amendment challenge brought by food industry members, it is essential to first determine how a court would analyze such a challenge. However, the analysis of whether the Central Hudson or Zauderer standard would apply to the added sugar disclosure cannot begin without first determining whether the disclosure is considered commercial speech.

\section{A. Commercial Speech Analysis}

To determine if speech is commercial speech, a court will consider three factors: "(1) whether the speech is an advertisement; (2) whether it refers to a specific product; and (3) whether the speaker has an economic motivation for speaking." 135 The three factors do not only apply to situations that involve actual speech. ${ }^{136}$ The Sixth Circuit found disclosures on food labels to be commercial speech in the 2010 International Dairy decision. ${ }^{137}$ Food labels typically present a commercial transaction for purchase and even when the label contains a disclosure, courts have considered them to be commercial speech. ${ }^{138}$ The Nutrition Facts label presents a commercial transaction for purchase; therefore even if it contains the added sugar disclosure, it is likely commercial speech.

\section{B. Zauderer or Central Hudson}

After the determination that the added sugar disclosure is commercial speech, the next step is to evaluate whether the test from Zauderer or Central Hudson should apply to a

135 Melissa M. Card, America, You are Digging Your Grave with Your Spoon-Should the FDA Tell You That on Food Labels?, 68 FoOD \& DRUG L.J. 309, 313 (2013).

${ }^{136} \mathrm{Id}$.

137 See Int'l Dairy Foods Ass'n v. Boggs, 622 F.3d. 628, 635 (6 ${ }^{\text {th }}$ Cir. 2010); See also Card, supra note 135, at 314.

138 Card, supra note 135 , at 314. 
First Amendment challenge in this context. The determination is best made after quickly reviewing the recent case law involving commercial speech litigation discussed earlier. Currently, courts are split as to which standard should be applied to commercial speech cases that involve labels of products regulated by the FDA. 139

\section{Central Hudson Standard Analysis}

The Central Hudson standard was the most widely used standard for commercial speech cases in the past, but appears to have been used less often in recent cases. As previously discussed, the D.C. Circuit applied the intermediate scrutiny test from Central Hudson to R.J. Reynolds Tobacco Co. in 2012 to evaluate the FDA's proposed use of graphic warnings on the labels of tobacco products. ${ }^{140}$ Under the Central Hudson standard, the D.C. Circuit found the FDA could not require this compelled speech in the form of graphic warnings on the labels. ${ }^{141}$ Further, the court rejected using the Zauderer standard because the graphic warnings were not "purely factual and uncontroversial." 142

When the FDA promulgated the final rule for adding the disclosure of trans fats to the Nutrition Facts label, it included a brief Central Hudson analysis in response to many public comments that asserted the disclosure would not pass the intermediate scrutiny test. ${ }^{143}$ In the analysis, the FDA claimed the disclosure would pass the first prong because the disclosure of trans fats is related to lawful activity and is not misleading. ${ }^{144}$ The disclosure also passed the second and third prongs because the mandatory trans fat disclosure directly advanced the substantial interests of protecting and promoting public health, as well as preventing consumer deception. ${ }^{145}$

139 Id.

140 See generally R.J. Reynolds Tobacco Co. v. FDA, 696 F.3d. 1205 (D.C. Cir. 2012).

141 Id.

142 Id.

143 Trans Fatty Acids, supra note 36, at 41439.

144 Id.

145 Id. at $41439-41440$. 


\section{Zauderer Standard}

Contrary to R.J. Reynolds Tobacco, the D.C. Circuit held American Meat Institute v. USDA to the Zauderer standard in the summer of 2014.146 The court's decision shifted from the use of Central Hudson by finding that Zauderer can apply to speech beyond situations of deception. ${ }^{147}$ The court also found that Zauderer could be extended to disclosures that are required to serve government interests other than preventing deception. ${ }^{148}$ Finally, the D.C. Circuit made a point to state that it now overrules the cases where Zauderer is read to only apply to disclosures where the government's interest is correcting deception. ${ }^{149}$

The Sixth Circuit also applied Zauderer to commercial speech cases that involve compelled speech through label disclosures. In International Dairy, the court evaluated a disclosure requirement on dairy products that claimed to be "rbST free" under Zauderer in 2010.150 The Sixth Circuit found Zauderer to be the appropriate standard because it is applicable to disclosures that are required based on the government's interest to correct potentially misleading speech and not just inherently misleading speech. 151

Because litigation arising from compelled disclosures on food labels has most recently been decided under Zauderer, it appears that a court would hold the added sugar disclosure to the same standard. The court's effort in American Meat Institute that overruled the cases that only apply Zauderer to cases to correct deception is dispositive in the determination of which standard a court would apply to the added sugar disclosure, even though the FDA previously used the Central Hudson standard to self evaluate a mandatory disclosure. Further, the FDA even stated in their self-evaluation of the trans fat disclosure that the disclosure

146 Am. Meat Inst., v. United States Dep’t of Agric., 760 F.3d. 18, at 20 (D.C. Cir. 2014).

147 Id.

$148 I d$. at 21.

149 Id. at 22.

150 Int'l Dairy Foods Ass'n v. Boggs, 622 F.3d. 628, 640 (6 $6^{\text {th }}$ Cir. 2010).

151 Id. at 641. 
likely did not need to be analyzed under the intermediate scrutiny test from Central Hudson. ${ }^{152}$

Additionally, Judge Rodgers expressed his dissatisfaction with the use of Central Hudson in his dissent in R.J. Reynolds Tobacco, stating that Zauderer should have applied instead. ${ }^{153}$ Rodgers' assertion that Central Hudson was not appropriate to evaluate the graphic warning labels supports a finding that Zauderer is the correct standard for analyzing the less dramatic added sugar disclosure proposed by the FDA.

Further, the fact that the public comments asserted Central Hudson as the standard to be applied to the disclosure does not weigh on the analysis in this Note. ${ }^{154}$ The added sugar disclosure is purely factual and uncontroversial and even though the government's interest in the disclosure may be beyond correcting deception, American Meat Institute opened the door for Zauderer to be extended to government interests beyond correcting deception.

\section{Zauderer First Amendment Analysis}

After establishing Zauderer as the appropriate standard to evaluate the added sugar disclosure, each of the five factors of the reasonable relationship test should be applied to the added sugar disclosure.

152 Trans Fatty Acids, supra note 36, at 41440.

153 R.J. Reynolds Tobacco Co. v. FDA, 696 F.3d. 1205, 1222 (D.C. Cir. 2012) (Rodgers, J., dissenting) ("[i]n affirming the grant of summary judgment to the tobacco companies, the court applies the wrong level of scrutiny").

154 Public Comment from the Corn Refiner's Association on Proposed Rule: Food Labeling: Revision of the Nutrition and Supplement Facts Labels (Aug. 1, 2014), available at http://www.regulations.gov/ \#!documentDetail;D=FDA-2012-N-1210-0455 [http://perma.cc/8LK6Y3H2]V9L2-XQ6Y]. The association attempts to claim that the added sugar disclosure would fail on all four prongs of the Central Hudson test and Zauderer cannot apply because the FDA has failed to show any value the disclosure of added sugar would provide for consumers. 


\section{Purely Factual}

The first prong of the Zauderer test is to determine whether the disclosure is purely factual. ${ }^{155}$ Zauderer demonstrates that disclosures or speech that contain accurate, factual information are considered to be purely factual. 156 Based on this description of purely factual, it appears the added sugar disclosure passes the first prong. The FDA's proposed disclosure requires a statement of the amount of sugar the food manufacturer has contributed to the product, which is simple, factual information. ${ }^{157}$

A comparison of the added sugar disclosure with the country-of-origin disclosure provides further support for the FDA's purely factual argument. The two disclosures appear to be comparable because of the similar basic structure of each disclosure. The country-of-origin disclosure was an undisputed simple, accurate statement regarding the location of origin of a meat product, held by the court to be purely factual. 158

The added sugar disclosure is the same type of simple, accurate information as the country-of-origin disclosure and should therefore also be considered purely factual. The added sugar disclosure should also be considered purely factual when compared to the graphic warning labels on tobacco products that Judge Rodgers claimed to be factual in his dissent. 159

\section{Uncontroversial}

The second prong in the Zauderer reasonable relationship test is to determine whether the disclosure or speech is uncontroversial. ${ }^{160}$ The FDA may have the most difficultly

155 Dhooge, supra note 37 , at 624.

156 Id.

157 Food Labeling, supra note 14, at 11884.

158 Am. Meat Inst. v. United States Dep't of Agric., 760 F.3d. at 18, 20 (D.C. Cir. 2014).

159 R.J. Reynolds Tobacco Co. v. FDA, 696 F.3d. 1205, 1222 (D.C. Cir. 2012) (Rodgers, J., dissenting).

160 Dhooge, supra note 37, at 624. 
passing this prong because many food industry members strongly oppose the added sugar disclosure as highly controversial in the public comments.

The FDA relied on scientific evidence that "many foods and beverages that are major sources of added sugars have low levels of nutrients, such as vitamins" to support its assertion that the added sugar disclosure is uncontroversial. ${ }^{161}$ The FDA asserted the added sugar disclosure is uncontroversial because consumers may incorrectly believe foods to be full of vitamins and nutrients that are in fact diminished when the sugar was added to the food. 162

Although the FDA relied on scientific evidence to support the disclosure as uncontroversial, the opponents argue there is a lack of evidence to support the added sugar disclosure. The Sugar Association, one of the major opponents of the disclosure, claimed that when the Dietary Guidelines for Americans Council made their determination that added sugars contribute to obesity, weight gain, and heart disease in 2010, there was no strong or conclusive evidence to support the findings. ${ }^{163}$ However, a 2015 scientific report released by the Dietary Guidelines Advisory Committee provided evidence "suggesting a strong association between a dietary pattern of intake characterized, in part, by a reduced intake of added sugars and a reduced risk of cardiovascular disease." 164

Further, some opponents claimed there was a lack of evidence to show the body processes added sugar any differently than natural sugars-an assertion the FDA did

161 Proposed Nutrition Facts Label Changes Are Based On Science And Research, U.S. FOOD AND DRUG ADMINISTRATION, available at http://www.fda.gov/forconsumers/consumerupdates/ucm387164.htm

[http://perma.cc/Q4PK-BCL7] (last updated Sept. 1, 2015) [hereinafter "Science and Research"].

162 Id.

163 The Sugar Association Calls for Withdrawal of 'Added Sugars' Labeling Proposal in Comments Filed to FDA, THE Sugar Association (Jul. 31, 2014), http://www.sugar.org/sugar-association-calls-withdrawaladded-sugars-labeling-proposal-comments-filed-fda/

[http://perma.cc/9LC8-CBUE] [hereinafter "Sugar Association"].

164 Supplemental Proposed Rule, supra note 20, at 44303. 
not dispute when it published the proposed rule. ${ }^{165}$ Although the FDA conceded on this issue, supporters of the added sugar disclosure countered the argument with an assertion that even if there is "no differing physiological effect for added versus naturally present sugar," lack of differing effects is not a relevant point to the required disclosure. 166 Instead, supporters asserted the main point of the disclosure is to bring attention to the overconsumption of sugar among consumers. 167 If such an assertion is accepted as true, the disclosure is not controversial when used to encourage consumer awareness. ${ }^{168}$

The similar country-of-origin disclosure was considered uncontroversial because there was no dispute over the truth of the facts contained in the disclosure. ${ }^{169}$ It does not appear that the opposition to the added sugar disclosure disputes the truthfulness of the amount of added sugar in a product; therefore the added sugar disclosure is uncontroversial as well. Further, the added sugar disclosure is much less radical than the proposed graphic warning label that tobacco companies found to be very controversial.

\section{Legitimate Government Interest}

The third prong of the reasonable relationship test from Zauderer requires a legitimate government interest for compelling the disclosure. ${ }^{170}$ The FDA asserted several interests to support the added sugar disclosure, but perhaps the most legitimate was to improve consumer health and

165 Food Labeling, supra note 14, at 11905 (Noting "[w]e continue to recognize the lack of a physiological distinction between added and naturally occurring sugars.").

166 Gretchen Goldman, Five Things Sugar Interests Get Wrong About FDA Added Sugars Labeling, FoOD SAFETY NeWs (Jul. 3, 2014), http://www.foodsafetynews.com/2014/07/goldman-contributed/\#.VFPkY_

nF-nF [http://perma.cc/3WXD-JPPU].

167 Id.

$168 I d$.

169 See Am. Meat Inst., v. United States Dep't of Agric., 760 F.3d. at 27 (D.C. Cir. 2014).

170 Dhooge, supra note 37, at 624 . 
access to healthy food choices. ${ }^{171}$ Americans are facing a health crisis with the rise of the obesity epidemic, despite the government's efforts to alleviate the crisis. Current data reveals about sixty-eight percent of adults are overweight or obese ${ }^{172}$ - which in turns leads to high rates of other chronic diseases, such as heart disease, type II diabetes and even some types of cancer. ${ }^{173}$ The chronic diseases typically caused as a result of obesity are currently the leading causes of death in the United States. ${ }^{174}$

Society as a whole has an interest in reducing the obesity rate. The FDA has set out to take part in reducing the obesity rate through the update of a Nutrition Facts label to "help consumers make informed food choices to consume a nutritionally adequate diet while monitoring calorie intake and lowering their risk of some chronic diseases." 175

Consumers are in need of additional information in order to efficiently make healthy choices for a healthy lifestyle. The additional information is most efficient if it is available to consumers on the labels, and therefore the government has a legitimate interest in requiring the disclosure of added sugar. ${ }^{176}$ The interest of improving consumer health through availability of necessary information on added sugar is supported by evidence from the Dietary Guidelines for Americans Council that revealed "added sugars ... make[s] up a significant percentage of the American diet and are a source of excess calories." 177

The government asserted a similar interest in providing the necessary tools for consumers to make informed and healthy choices by implementing the country-of-origin disclosure. There was a legitimate government interest to provide consumers with information that would give them

171 Food Labeling, supra note 14, at 11881.

172 Id. at 11885.

173 Id. ("An estimated 37 percent of Americans suffer from cardiovascular disease (CVD), 11.3 percent of the population 20 years and older has diabetes, 35 percent of adults has pre-diabetes, and 41 percent of the population is predicted to be diagnosed with cancer during their lifetime.").

174 Id.

175 Id.

176 Id.

177 Id. at 11904. 
the opportunity to choose to purchase American raised meat through a disclosure similar to the added sugar disclosure. ${ }^{178}$

In addition to improving consumer health and increasing access to healthier food choices, the government has an interest in encouraging changes in food processing, a change endorsed by supporters such as the Obesity Society. ${ }^{179}$ The food industry has continually made changes to the way food is produced and manufactured since the introduction of the Nutrition Facts label through the NLEA. ${ }^{180}$ With the rise in the obesity epidemic, it is important to continue to make the necessary changes to the make-up of food, and as the past has shown, disclosure of unhealthy ingredients is a good motivator of change for the food industry. ${ }^{181}$

The FDA has an additional legitimate interest for requiring the disclosure of added sugars; the improvement of consumer awareness. As consumers become interested in reducing caloric intake and increasing the amount of nutrient dense foods, the government has a legitimate interest in supporting consumer interest through the added sugar disclosure. ${ }^{182}$ Without including added sugar on the Nutrition Facts label, many consumers are unable to determine which foods are high in unnatural sugars and which are not-a consideration that strengthens the FDA's interest in promoting awareness. ${ }^{183}$

Finally, the FDA may have a legitimate government interest in preventing consumer deception. Although

178 Am. Meat Inst., v. United States Dep't of Agric., 760 F.3d. at 18, 23 (D.C. Cir. 2014) (The "context and long history of country of origin disclosures to enable consumers to choose American made products.").

179 The Obesity Society Supports all Proposed Changes to Food Nutrition Facts Labels and Commends the U.S. Food \& Drug Administration for the Much-Needed Update, THE OBESITY SOCIETY (May 15, 2014), http://www.obesity.org/proposed-major-revision-to-foodnutrition-facts-labels.htm [http://perma.cc/7WRG-HGHN] [hereinafter Obesity Society].

180 Proposed Changes, supra note 4.

$181 \mathrm{Id}$. An example of a disclosure that led to an improved formulation of food products is when the FDA began requiring the amount of trans fats on the Nutrition Facts label, the amount food manufacturers used decreased.

182 Food Labeling, supra note 14, at 11905.

183 Id. at 11904. 
American Meat Institute allows disclosures that are not aimed at preventing or correcting deception to be held to the Zauderer standard, 184 it may still be one of the FDA's purposes for requiring the added sugar disclosure. As discussed earlier, consumers may incorrectly assume that a food does not contain added sugar because of a front of package label that categorizes the food as healthy. 185 The added sugar disclosure allows consumers to correctly identify foods that contain added sugar versus natural sugar, and avoid mistaking a food as healthy when it actually contains a high amount of added sugar.

In summary, there is a legitimate government interest in requiring the disclosure of added sugar on the Nutrition Facts label because of the need to improve consumer health and access to healthier food choices. Additionally, there is a legitimate interest in improving the way food is manufactured, as well as improving consumer awareness of the ingredients in food through the disclosure of added sugar. Finally, the FDA has an interest in preventing potential consumer deception.

\section{Disclosure Must Be Reasonably Related}

The fourth prong of the reasonable relationship test from Zauderer requires the added sugar disclosure to be reasonably related to the legitimate government interests asserted in the third prong. ${ }^{186}$ First, the added sugar disclosure is reasonably related to the government interest of improving consumer awareness because evidence reveals that many consumers actually read and use the Nutrition Facts label. ${ }^{187}$ In fact, the number of consumers that report reading the Nutrition Facts labels increased ten percent in

184 Am. Meat Inst. v. United States Dep't of Agric., 760 F.3d. 18, 20 (D.C. Cir. 2014).

185 Point of Package Labeling, supra note 25.

186 Dhooge, supra note 37, at 624.

187 See Food Labeling, supra note 14, at 11887. 
six years. ${ }^{188}$ The increase is confirmation that the disclosure will affect more consumers than the food industry believes. ${ }^{189}$

Further, the added sugar disclosure on the Nutrition Facts label is reasonably related to the government interest of improving consumer awareness because the flow of information is an important method of creating awareness. Without the amount of added sugar on the Nutrition Facts label, the consumer would not be able to discern between naturally and unnaturally occurring sugars in a food product, thus hindering their ability to make informed decisions when searching for healthy food choices. ${ }^{190}$

The added sugar disclosure is reasonably related to the government interest of changing the way food is processed. By improving the way food is processed, more healthy food options with less added sugar will be available for consumers. The increased availability of healthy foods will improve access to healthy choices, as well as improve overall consumer health. 191 In addition to improving access and health, history has shown that requiring the disclosure of an unhealthy ingredient is related to altering the way some foods are produced. When the FDA began requiring the disclosure of trans fats in 2003, the amount of trans fats that food manufacturers used lowered dramatically and in some cases was completely removed from foods. 192

Before declaring the disclosure reasonably related to the legitimate interests, it is important to consider the opposition's reasoning for why the disclosure is not reasonably related to the government interest. The opposition attacks the FDA's main interest of improving consumer health because the disclosure is not reasonably related to improving health through a reduction of excess calorie consumption due to added sugar intake. ${ }^{193}$ The Sugar

188 See id. ("The percentage of consumers reporting that they often read a food label the first time they purchase a food product rose from 44 percent in 2002 to 54 percent in 2008.”).

189 Id.

190 Food Labeling, supra note 14, at 11904.

191 Proposed Changes, supra note 4.

192 Goldman, supra note 166.

193 Sugar Association, supra note 163. 
Association highlights there is no official recommendation for the amount of added sugar individuals should consume. ${ }^{194}$ Further, they assert the "average American consumes 300 calories of added sugar per day" 195 and therefore the disclosure will only affect a small number of consumers and is not reasonably related to the government interests. ${ }^{196}$ However, the 2015 Scientific Report of the Dietary Guidelines Advisory Committee made a recommendation to limit added sugar intake to less than ten percent of overall caloric intake. ${ }^{197}$

Although the opposition provides valid arguments to consider, the arguments do not outweigh the support that the disclosure is reasonably related to the government interests. The FDA also has support for their argument from the D.C. Circuit's finding that the country-of-origin disclosure was reasonably related to the legitimate government interests. 198 The D.C. Circuit pointed out the disclosures were reasonably related to legitimate interests when they provided "purely factual and uncontroversial information about attributes of the product or service being offered." 199 Because the added sugar disclosure is similar to the country of origin disclosure and has already been determined to be purely factual and uncontroversial, the added sugar disclosure is reasonably related to the FDA's legitimate interests.

The added sugar disclosure is reasonably related to the legitimate interests of improving consumer health through enhancing awareness of food content and access to healthy food options, as well as encouraging change in the way food is produced and manufactured. Accordingly, the disclosure will move on to the fifth and final prong of the reasonable relationship test.

194 Id.

195 Tavernise, supra note 21.

196 Id.

197 Supplemental Proposed Rule supra note 20, at 44308.

198 See Am. Meat Inst. v. United States Dep't of Agric., 760 F.3d. 18, 26 (D.C. Cir. 2014).

199 Id. (The court also stated that a disclosure will usually be reasonably related to the government interests, "absent a showing that the disclosure is 'unduly burdensome' in a way that 'chill[s] protected commercial speech,") (quoting Edenfeld v. Fane, 507 U.S. 761, 651 (1993)). 


\section{Disclosure Is Not Unjustified or Unduly Burdensome}

The fifth and final prong of the reasonable relationship test from Zauderer requires that the disclosure is not unjustified or unduly burdensome. To determine whether or not the added sugar disclosure is unjustified or unduly burdensome, the analysis begins by examining some of the reasons why opponents argue the disclosure is unjustified or unduly burdensome. First, opponents asserted there is no analytical method to distinguish between added and naturally occurring sugars in a food. ${ }^{200}$ The same opponents also raised the argument that there is no analytical method to distinguish between the two types of sugars, therefore disclosure would require "unprecedented record keeping," that would be unduly burdensome on food manufacturers. 201

The FDA and supporters of the added sugar disclosure reject the Sugar Association's claims with several points. First, the FDA and supporters assert that since manufacturers are responsible for adding the extra sugar to the food products, they should have an idea of how much sugar is added during processing. ${ }^{202}$ If manufacturers have knowledge of the amount of added sugar they are adding during processing, there is no need for analytical methods that would lead to burdensome record keeping. ${ }^{203}$ The FDA also asserted that the alleged lack of analytical methods should not preclude the promulgation of a final rule because the FDA could achieve the record keeping through maintenance and record review. ${ }^{204}$ Further, the FDA has required similar record keeping in the past for food products,

200 Sugar Association, supra note 163.

201 Id. The Sugar Association asserts the disclosure cannot be enforced without such "unprecedented record keeping and inspection requirements."

202 Goldman, supra note 166.

203 Id.

204 Food Labeling, supra note 14 at 11905. (The FDA has requested the review of records for values of dietary fiber, folate, and vitamin $\mathrm{E}$ under certain circumstances, implying the records will not be used solely for review of added sugars.) 
which rejects the opponents' idea that the record keeping would be unprecedented. ${ }^{205}$

In addition to the Sugar Association's burdensome record keeping argument, other opponents of the disclosure claimed it is unjustified because it may deceive consumers into purchasing foods that may be lower in added sugar but are actually higher in calories and fat. ${ }^{206}$ The opponents also alleged that the extra line for added sugar on the label would confuse consumers because they may add the two lines of sugar together. ${ }^{207}$ If consumers add both sugar lines together, they may be misled into believing a product contains more sugar than it actually does. ${ }^{208}$

The FDA conceded on the issue of initial confusion, but instead asserted the lack of consumer understanding about how to read the two sugar lines will be resolved with consumer education over time.209 The FDA's idea for such education is through consumer studies in the form of questionnaires on the understanding of the use of the added sugar disclosure. ${ }^{210}$ The FDA maintained that the consumer studies would be referred to for future actions related to the added sugar disclosure. ${ }^{211}$ As support for resolving the consumer confusion, the FDA's consumer studies were completed before the publishing of the 2015 revisions and revealed that the majority of consumers were able to correctly identify the amount of total sugar and added sugar when both were listed separately on the label. ${ }^{212}$

Finally, the FDA asserted the disclosure is not unjustified or unduly burdensome because of the generous amount of

$205 I d$. (requiring record keeping with respect to the aeration to reduce fat in foods).

206 Sugar Association, supra note 163.

207 Lammi, supra note 32.

208 Id.

209 Food Labeling, supra note 14, at 11905. (The FDA has previously used explanatory footnotes on labels, such as describing the amount of calories the daily value percentage is based on. Additionally, the FDA emphasizes that the two sugar lines are independent of each other and are necessary for consumers to compare the amount of added sugar in different foods.).

210 Id. at 11905.

211 Id.

212 Supplemental Proposed Rule supra note 20, at 44306. 
time being allotted for food industry members to become compliant with a final rule. ${ }^{213}$ The time for implementation for the proposed rule, including the added sugar disclosure is two years from the date of the implementation of a final rule. ${ }^{214}$

The disclosure of added sugar on the Nutrition Facts label passes the final prong of the reasonable relationship test because it is not unjustified or unduly burdensome. Food manufacturers should be able to record the amount of added sugar included in food products during processing because the FDA has required similar record keeping requirements in the past related to food labeling.

Additionally, the disclosure is not unjustified or unduly burdensome because the FDA plans to address the possible consumer confusion with educational pieces to describe how to read the new Nutrition Facts label. Finally, the FDA has granted a generous amount of time for food manufacturers to become compliant with the final rule. ${ }^{215}$ In conclusion, the disclosure is not unjustified or unduly burdensome.

\section{Final Policy Reasons for Implementing the Proposed Rule}

Despite the threat of First Amendment litigation from food industry members and regardless of the standard used to analyze the added sugar mandatory disclosure in anticipation litigation, there are a number of policy reasons for why the FDA should promulgate a final rule. The need for updated Nutrition Facts labels is essential to public health. Commentators point out that Americans have the "sweetest diet in the world" and the added sugar disclosure is necessary to make consumers aware of this diet. ${ }^{216}$

Additionally, one of the FDA's goals behind the updated label is to empower consumers to make healthy choices,

213 Id. at 11882.

214 Id.

215 Food Labeling, supra note 14, at 11959 (Manufacturers have two years from the effective date of a Final Rule to be in compliance with the regulations.).

216 Tavernise, supra note 21. 
rather than explicitly telling consumers what they should eat. ${ }^{217}$ In a society that is constantly seeking transparency from the government, consumers should have the opportunity to make an educated decision on whether or not to consume a glass of apple juice if it contains ten grams of added sugar.

Further, consumers should be able to make such educated decisions without a complex educational background in nutrition science. ${ }^{218}$ The update to the Nutrition Facts label provides a simplified label that allows consumers to determine whether the sugar in fruit juice came from the fruit itself, without having to interpret scientific names for sugar in the ingredients list.

Finally, food labeling practices and policies should be updated every so often in order to remain effective. As technology changes and more is learned about the way certain foods affect individual health, the information that is presented to consumers must also be updated.219 As consumer lifestyles and food consumption trends change, the information provided to the consumer must reflect these changes. ${ }^{220}$

The policy reasons for including the added sugar disclosure provide further support for the FDA to march on with a final rule implementing the disclosure, along with the rest of the proposed changes to the Nutrition Facts label.

\section{CONCLUSION}

The added sugar disclosure on the Nutrition Facts label, as proposed in "Food Labeling: Revision of the Nutrition and Supplement Facts Label," will be analyzed under the more lenient reasonable relationship test created in Zauderer. ${ }^{221}$ American Meat Institute frames the standard so that it can

217 Obesity Society, supra note 179.

218 Tavernise, supra note 21. (First Lady Michelle Obama emphasized the importance of enabling consumers to be able to look at products at the grocery store and quickly determine whether it is a healthy choice).

219 See Science and Research supra note 161.

$220 I d$.

221 See Id. 
be applied in cases where the government has an interest beyond preventing consumer deception through purely factual information, ${ }^{222}$ such as the added sugar disclosure.

While the opponents of the added sugar disclosure may have some compelling arguments, the FDA's proposed rule will still withstand First Amendment challenges because it passes the five prongs of the reasonable relationship test from Zauderer. The disclosure is purely factual and uncontroversial and the government has a legitimate interest in mandating the disclosure. The added sugar disclosure is reasonably related to the legitimate interests and finally, the disclosure is not unjustified or unduly burdensome.

In addition to passing the Zauderer test, it is apparent the updated Nutrition Facts label is necessary as one of many steps to help combat the obesity crisis the United States is currently facing. Even without a First Amendment analysis under either standard, the FDA should press on with a final rule, based on the strong policy reasons. With such a frightening obesity crisis, even the slightest chance that the updated Nutrition Facts label will motivate consumer change should be enough to move forward with the rule.

Finally, the FDA could take the same cautious step it took when promulgating the trans fat disclosure by including a Zauderer analysis in the published final rule. Such an analysis would be in response to the public comments that assert First Amendment violations. However, even without such an analysis in the final rule, the added sugar disclosure will likely withstand First Amendment challenges because of the legitimate public health need for the disclosure. ${ }^{223}$

222 Am. Meat Inst., v. United States Dep’t of Agric., 760 F.3d. 18, at 22 (D.C. Cir. 2014).

223 Tavernise, supra note 21 (referring to President George Bush's statement that the proposed changes are "one of the most important public health upgrades in this decade"). 